\title{
Diagnostic Accuracy of Confocal Laser Endomicroscopy for the Diagnosis of Oral Squamous Cell Carcinoma: A Systematic Review and Meta-Analysis
}

\author{
Sneha Sethi ${ }^{1, *(\mathbb{D})}$, Xiangqun Ju ${ }^{1} \mathbb{D}$, Richard M. Logan ${ }^{2} \mathbb{D}$, Paul Sambrook ${ }^{2,3}$, Robert A. McLaughlin ${ }^{4,5,6} \mathbb{D}$ \\ and Lisa M. Jamieson ${ }^{1}$
}

1 Australian Research Centre for Population Oral Health, Adelaide Dental School, Faculty of Health and Medical Sciences, University of Adelaide, Adelaide, SA 5005, Australia; xiangqun.ju@adelaide.edu.au (X.J.); lisa.jamieson@adelaide.edu.au (L.M.J.)

2 Adelaide Dental School, Faculty of Health and Medical Sciences, University of Adelaide, Adelaide, SA 5005, Australia; richard.logan@adelaide.edu.au (R.M.L.); paul.sambrook@adelaide.edu.au (P.S.)

3 Oral and Maxillofacial Surgery Unit, SA Dental Service, Adelaide, SA 5005, Australia

4 School of Biomedicine, Faculty of Health and Medical Sciences, University of Adelaide, Adelaide, SA 5005, Australia; robert.mclaughlin@adelaide.edu.au

5 Australian Research Council Centre of Excellence for Nanoscale Biophotonics, The University of Adelaide, Adelaide, SA 5005, Australia

6 Institute of Photonics and Advanced Sensing, The University of Adelaide, Adelaide, SA 5005, Australia

* Correspondence: sneha.sethi@adelaide.edu.au

\section{check for} updates

Citation: Sethi, S.; Ju, X.; Logan, R.M.; Sambrook, P.; McLaughlin, R.A.; Jamieson, L.M Diagnostic Accuracy of Confocal Laser Endomicroscopy for the Diagnosis of Oral Squamous Cell Carcinoma: A Systematic Review and Meta-Analysis. Int. J. Environ. Res. Public Health 2021, 18, 12390. https:// doi.org/10.3390/ijerph182312390

Academic Editor: Amerigo Giudice

Received: 5 October 2021

Accepted: 18 November 2021

Published: 25 November 2021

Publisher's Note: MDPI stays neutral with regard to jurisdictional claims in published maps and institutional affiliations.

Copyright: (c) 2021 by the authors. Licensee MDPI, Basel, Switzerland. This article is an open access article distributed under the terms and conditions of the Creative Commons Attribution (CC BY) license (https:/ / creativecommons.org/licenses/by/ $4.0 /)$.
Abstract: Background: Advances in treatment approaches for patients with oral squamous cell carcinoma (OSCC) have been unsuccessful in preventing frequent recurrences and distant metastases, leading to a poor prognosis. Early detection and prevention enable an improved 5-year survival and better prognosis. Confocal Laser Endomicroscopy (CLE) is a non-invasive imaging instrument that could enable an earlier diagnosis and possibly help in reducing unnecessary invasive surgical procedures. Objective: To present an up to date systematic review and meta-analysis assessing the diagnostic accuracy of CLE in diagnosing OSCC. Materials and Methods. PubMed, Scopus, and Web of Science databases were explored up to 30 June 2021, to collect articles concerning the diagnosis of OSCC through CLE. Screening: data extraction and appraisal was done by two reviewers. The quality of the methodology followed by the studies included in this review was assessed using the Quality Assessment of Diagnostic Accuracy Studies-2 (QUADAS-2) tool. A random effects model was used for the meta-analysis. Results: Six studies were included, leading to a total number of 361 lesions in 213 patients. The pooled sensitivity and specificity were $95 \%\left(95 \% \mathrm{CI}, 92-97 \% ; \mathrm{I}^{2}=77.5 \%\right)$ and 93\% (95\% CI, 90-95\%; $\left.\mathrm{I}^{2}=68.6 \%\right)$; the pooled positive likelihood ratios and negative likelihood ratios were $10.85\left(95 \% \mathrm{CI}, 5.4-21.7 ; \mathrm{I}^{2}=55.9 \%\right)$ and 0.08 (95\% CI, 0.03-0.2; $\left.\mathrm{I}^{2}=83.5 \%\right)$; and the pooled diagnostic odds ratio was $174.45\left(95 \% \mathrm{CI}, 34.51-881.69 ; \mathrm{I}^{2}=73.6 \%\right)$. Although risk of bias and heterogeneity is observed, this study validates that CLE may have a noteworthy clinical influence on the diagnosis of OSCC, through its high sensitivity and specificity. Conclusions: This review indicates an exceptionally high sensitivity and specificity of CLE for diagnosing OSCC. Whilst it is a promising diagnostic instrument, the limited number of existing studies and potential risk of bias of included studies does not allow us to draw firm conclusions. A conclusive inference can be drawn when more studies, possibly with homogeneous methodological approach, are performed.

Keywords: oral squamous cell carcinoma; confocal laser endomicroscopy; systematic review; meta-analysis; diagnostic test accuracy

\section{Highlights}

- Confocal Laser Endomicroscopy (CLE) has very high sensitivity and specificity for diagnosing Oral squamous cell carcinoma (OSCC); 
- Transference of the first experimental results of CLE in the oral cavity of humans into an effective and evidence based clinical setting is recommended;

- A conclusive statement can only be made when additional comparable studies with homogeneous methodological strategies will be undertaken.

\section{Introduction}

Head and neck squamous cell carcinoma (HNSCC) is the sixth most prevalent cancer [1] globally, contributing towards $5 \%$ of all human malignancies [2]. Incidence and mortality due to HNSCC in 2018 was reported as 890,000 and 450,000, respectively [3,4]. This reported incidence has continued to grow exponentially and it is expected to rise to 1.08 million cases a year by the year $2030[3,4]$. The majority of OSCC patients are treated by an appropriate amalgamation of surgery, radiation, and chemotherapy [5]. Despite advances in treatment strategies, patients with OSCC suffer from a poor prognosis due to frequent recurrences and distant metastases [6]. Early detection and prevention are crucial factors in achieving better prognosis of OSCC with an improved 5-year survival [7].

OSCC has a multifactorial aetiology, including tobacco consumption, alcohol habits and viral (e.g., human papillomavirus) infections [8]. Field cancerization is the most accepted theory among researchers and clinicians, which explains frequent recurrences and metastases in OSCC [9]. Slaughter et al. [10], defined field cancerization as "pre-neoplastic mucosal area composed of epithelial cells with genetic or epigenetic changes beyond the original invasive malignancy, resulting in patients having several malignancies in various stages of development." Potentially malignant lesions of the oral cavity include leukoplakia, oral submucous fibrosis, erythroplakia, and are characterised by white or red patches on the oral mucosa with epithelial histological changes ranging from hyperplasia to carcinoma in situ [11]. The malignant transformation rate of leukoplakia ranges from 0.13 to $34 \%$ [12] and the transformation rate for erythroplakia ranges from $1.1 \%$ to $40.8 \%$ [13]. Due to field cancerization, it is hypothesized that the entire oral mucosa will be exposed to the carcinogen, causing widespread premalignant and malignant changes [10]. This situation represents a dilemma to the surgeon and clinical cancer management team regarding the resection margins and treatment regimens, as complete resection of the tumour is essential for a good prognosis [14]. This emphasizes the need for an instrument that enables the evaluation of dysplastic lesions in-vivo, preventing the need for wide-spread preventive excision.

The inability to clearly define surgical margins intraoperatively in OSCC patients is the number one reason for the recurrence of primary tumours and leading to a debilitating recurrence and associated metastasis [15]. The current practices which help in determining surgical margins include visualisation, palpation, or frozen section histopathology [16]. Although frozen sections are accurate, they are associated with multiple drawbacks, including compromising the tissue integrity and being time consuming [17]. Avoiding unnecessary resection of healthy tissues is of utmost importance to the surgeons, due to the functional limitations post-operatively and severe impact on the quality of life of the patient $[18,19]$. This limitation also supports the requirement of an explicit and correct evaluation of the affected oral tissues preceding surgical resection.

An ideal solution to these problems would-be real-time histological evaluation by an instrument, which is non-invasive, time efficient, and sensitive enough to replace the gold standard of histopathology. This concept has been previously explored using narrow-band imaging [20,21], autofluorescence imaging [22,23], computed tomography [24], and confocal imaging [25]. The latter study was done with a handheld confocal laser endomicroscope comprising of a bundle fibre probe (Manua Kea Cellvizio) with IV fluorescein as the fluorescent dye. This technique allowed efficient visualization of the epithelial architecture with a fluorescent contrast on the intraoperative display [26]. A fluorescent contrast agent intensifies the contrast of cells, which are imaged with a blue laser. Confocal Laser Endomicroscopy, aka "optical biopsy", is used to deliver the surgeon with real-time cellular resolution digital images ( $1 \mu \mathrm{m}$ to a 1000-fold magnification) during surgical procedures, 
allowing effective analysis of the surgical margins and ensuring improved precision in the determination of tumour resection margins and preventing recurrence. This medical imaging modality enables an in vivo diagnosis and images can be acquired almost indefinitely whilst avoiding any iatrogenic harm to the patient.

Previously, CLE has shown effective imaging whilst diagnosing gastrointestinal neoplasia's including Barrett's oesophagus $[27,28]$, intraepithelial neoplasia's of the colorectal tract [29,30], pre-neoplastic and neoplastic lesions of the cervical epithelium [31,32], neoplastic lesions involving the bronchial epithelium [33-35], neoplastic lesions of the urothelial epithelium $[36,37]$ and lesions of the brain or spinal cord [38-40]. The first report of CLE utility in the head and neck region, along with morphological associations with analogous H\&E stained tissue sections, was described in 1999 [41], followed by multiple in vivo and in vitro studies [42-50].

To articulate comprehensive and conversant evidence-based recommendations for the coherent use of CLE, a systematic review and meta-analysis was designed, to assess the precision in the diagnosis of OSCC using histopathology as the reference standard.

\section{Materials and Methods}

A systematic review and meta-analysis was performed and the results were described according to the standard Preferred Reporting Items for Systematic Reviews and MetaAnalysis (PRISMA) statement [51]. The review protocol was registered in the PROSPERO International Prospective Register of Systematic Reviews (CRD42021278405).

\subsection{Study Objective and Definition of Reference Standard}

The search strategy followed the PICO (population, intervention, comparison, and outcome) guidelines [52]. The population comprised of OSCC patients; OSCC can be defined as squamous cell carcinomas in the oropharynx and oral cavity including tongue, palate, etc. The intervention used was the use of CLE for diagnosis of OSCC. True positives (TP), false positives $(\mathrm{FP})$, true negatives $(\mathrm{TN})$, and false negatives (FN) were the outcomes measured while detection of OSCC using histology were the reference standard. A diagnosis subsequent to histopathological analysis of a biopsy specimen (incisional or excisional) was considered. The study design had no limitations, as long as original data were specified. The main objective of this systematic review and meta-analysis was to assess the accuracy of CLE for the diagnosis of OSCC.

\subsection{Literature Search Strategy}

Block search was carefully chosen as the search strategy, as it adhered to the PICO approach. A reviewer (S.S.) explored the following databases till 30 July 2021: PubMed (keywords "(oral squamous cell carcinoma)" OR "(Oral Cancer)" AND "(confocal microscopy"), Web of Science (keywords "TS = (confocal microscopy AND oral squamous cell carcinoma or Oral Cancer) Timespan: All years. Indexes: SCI-EXPANDED, SSCI, A\&HCI, CPCI-S, CPCI-SSH, BKCI-S, BKCI-SSH, ESCI, CCR-EXPANDED, IC.") and Elsevier-SCOPUS (keywords "TITLE-ABS-KEY ("confocal microscopy" AND "squamous cell carcinoma" OR "(Oral Cancer)"). All references were extracted and duplicates were removed using the reference manager EndNote (version X9, 2020, Clarivate, Philadelphia, PA, USA).

To evaluate the applicability of studies, two reviewers (S.S. and X.J.) independently screened all retrieved articles by titles first followed by abstracts to determine their relevance. Possibly eligible articles were analysed after full-text recovery. Incongruities were discussed with a third reviewer (LJ).

\subsection{Inclusion and Exclusion Criteria}

The established eligibility criteria were: (1) the CLE instrument used in the study should be based on the principle of Fluorescent Laser Endomicroscopy only; (2) the examined lesions were OSCCs (well differentiated, moderately differentiated, and poorly differentiated histopathological subtypes); (3) histopathological diagnosis of OSCC was the reference 
standard, following the examination of the biopsy specimen (incisional or excisional); (4) only human studies were included; (5) no case reports or reviews were included; (6) articles written in English were exclusively included.

We excluded from the analysis: (1) all studies using Reflectance Confocal Microscopy; (2) all basal cell carcinomas or corneal/optical epithelial tumours; (3) all studies based on cytological smears; (4) no animal-based models or trials were included; (5) studies where full-text and recovery was unlikely, including a search of the relevant databases and attempting communication with the corresponding authors. Studies with overlapping populations found in studies were also excluded, including a single study with the most representative data. Moreover, the reference list of all the papers were reviewed to ascertain additional appropriate studies that may have been unnoticed whilst initial screening was undertaken.

\subsection{Data Extraction}

A reviewer (S.S.) extracted the data from the included studies, which was additionally validated by another reviewer (X.J.). The variables extracted included: the name of the first author, country, year of publication, tumour sites (percent frequency), number of reviewers validating the CLE device, fluorescent agent used, total patients and lesions, patient sex and age (mean/median, years), sensitivity of instrument, specificity of instrument, and confocal criteria employed for the diagnosis of OSCC.

\subsection{Risk of Bias}

Risk of bias and quality of included studies was evaluated using the Quality Assessment of Diagnostic Accuracy Studies) QUADAS-2 checklist for primary studies assessing the diagnostic accuracy in four KEY domains; Patient Selection, Index Test, Reference Standard, and Flow and Timing [53]. All four domains are appraised for risk of bias, and only the first three domains are appraised for applicability concerns. The risk of bias was assessed to be either high, low, or unclear on the basis of the following questions: (1) if the reference standard was more likely to correctly diagnose OSCC (2) if a threshold for index-test was respecified; (3); whether the patient selection was a sequential or random sample of patients enrolled; (4) if there was an appropriate interval between index test and reference standard.

\subsection{Statistical Analysis and Meta-Analysis}

Tables were created for each CLE-based diagnosis of OSCC with histopathology diagnosis of incisional or excisional biopsy specimens. The sensitivity, specificity, and corresponding $95 \%$ confidence intervals were represented using forest plots. Diagnostic accuracy in terms of sensitivity, specificity, and diagnostic odds ratio with $95 \%$ confidence intervals was evaluated on the basis of TP, FP, TN, and FN extracted from each of the included studies.

Sensitivity was estimated as the proportion of patients, correctly identified by CLE as having OSCC, and specificity as the proportion of patients, correctly identified on radiology as not having OSCC. The diagnostic odds ratio was defined as the odds of the CLE diagnosis being positive for a patient having OSCC relative to the odds of the CLE test being positive for patients not having OSCC. Meta-analysis of sensitivity and specificity were determined by designing a bivariate model (hierarchical logistic regression) [54] and the Hierarchal summary receiver operating characteristic curve (HSROC) was created. The HSROC curve represents sensitivity vs. specificity graphically and provides evidence concerning the general test performance across different thresholds. Within study and between studies variability was determined by this model.

Heterogeneity is calculated as Higgins $\mathrm{I}^{2}$, where $\mathrm{I}^{2}=0 \%$ indicates no observed heterogeneity and $\mathrm{I}^{2}>50 \%$ is categorised as substantial heterogeneity. Heterogeneity is a prominent attribute observed in almost all meta-analyses of diagnostic accuracy tests, which can be explained by variation in the index test efficiency due to varied suggestive 
diagnostic thresholds. Statistical analysis of the sources of heterogeneity was not performed as the size of the subgroups were insignificant (two or three studies per group).

Data management and statistical analyses was performed using the software packages STATA (v15.0; StataCorp LP, College Station, TX, USA), Review Manager (v5.3; Copenhagen, Denmark) and MetaDisc (v1.4; Madrid, Spain).

\section{Results}

\subsection{Literature Search Results}

The preliminary database search recognized a total number of 2095 of articles. After removal of duplicates, only 1554 articles persisted. After title and abstract assessment, 1509 articles were disqualified and 45 were selected for full-text recovery and further analysis. Thirty-nine articles were excluded after full-text analysis illustrated in Figure 1. Six studies totaling a number of 361 lesions in 213 patients were included in the final analysis [25,55-59]. The study characteristics are tabulated in Table 1.

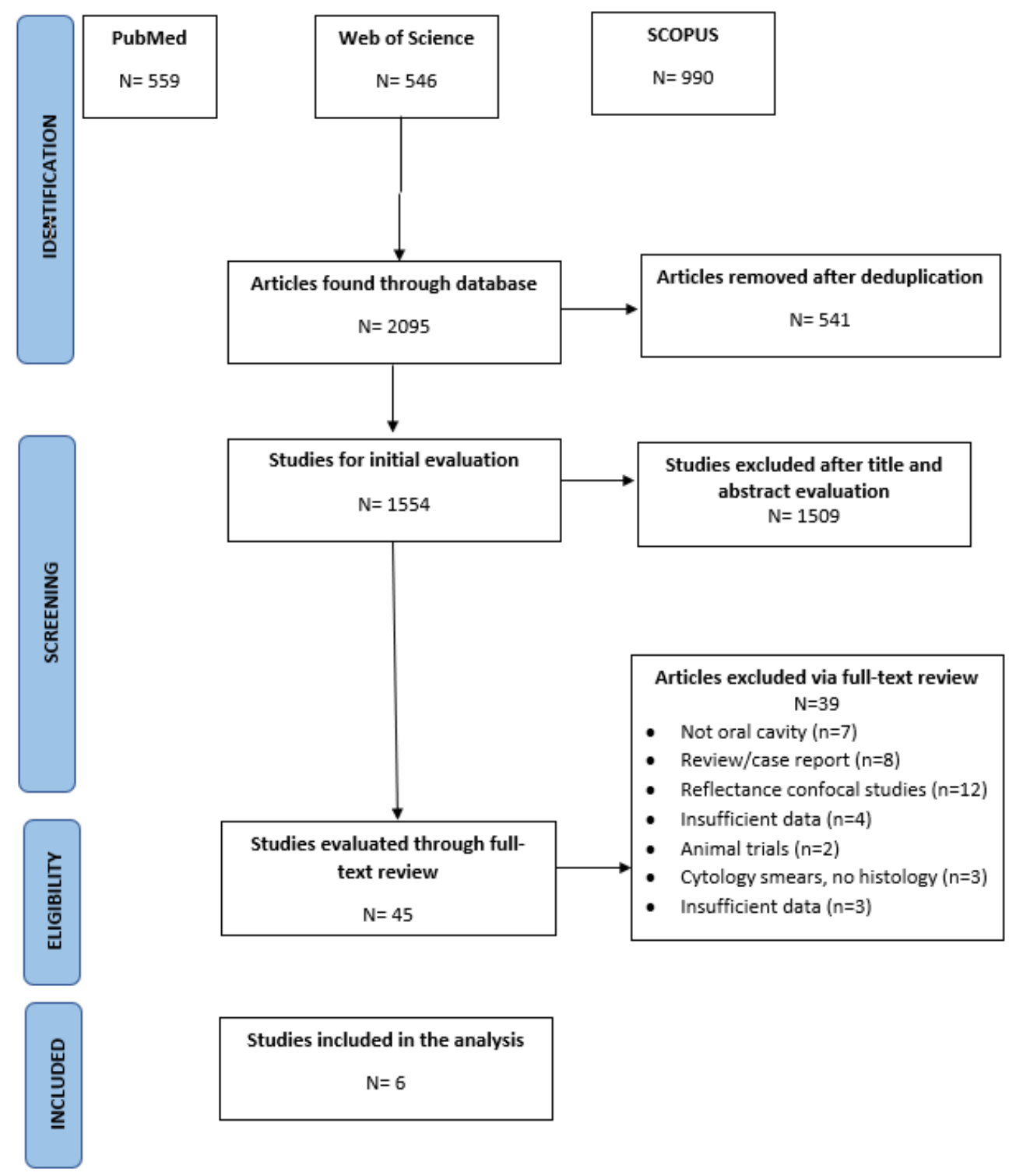

Figure 1. Screening process and results. Oral squamous cell carcinoma (OSCC). 
Table 1. Characteristics of included studies.

\begin{tabular}{|c|c|c|c|c|c|c|c|c|c|c|c|}
\hline Year & Author & Country & Site Distribution & $\begin{array}{c}\text { Examination } \\
\text { Setting }\end{array}$ & $\begin{array}{c}\text { Ni. of } \\
\text { Reviewers }\end{array}$ & CLE * Device & $\begin{array}{l}\text { Fluorescent } \\
\text { Agent Used }\end{array}$ & $\begin{array}{c}\text { Total } \\
\text { Patients }\end{array}$ & $\begin{array}{l}\text { Total } \\
\text { Sites }\end{array}$ & $\begin{array}{l}\text { Patient Gender } \\
\text { (\%) and Age } \\
\text { (Mean/Median) }\end{array}$ & Reference \\
\hline 2021 & $\begin{array}{l}\text { Dittberner A, } \\
\text { et al. }\end{array}$ & Germany & $\begin{array}{c}\text { Oropharynx }(52.9 \%), \\
\text { oral cavity }(55.3 \%), \\
\text { and hypopharynx }(11.8 \%) .\end{array}$ & In vivo & 2 & $\begin{array}{l}\text { CONVIVO, Carl } \\
\text { Zeiss AG, } \\
\text { Oberkochen, } \\
\text { Germany }\end{array}$ & Fluorescein & 13 & 30 & $\begin{array}{c}\text { Mean age-1.9 } \\
\text { years } \\
\text { M-69\% } \\
\text { F-31\% }\end{array}$ & Conventional histopathology \\
\hline 2020 & $\begin{array}{l}\text { Shinohara S, } \\
\text { et al. }\end{array}$ & Japan & $\begin{array}{c}\text { Hypopharynx }(30 \%), \text { larynx } \\
(10 \%) \text { lower gingiva }(20 \%), \\
\text { tongue }(20 \%), \\
\text { oropharynx }(20 \%)\end{array}$ & Ex vivo & $\mathrm{NS}^{*}$ & $\begin{array}{l}\text { FIGH-300S or } \\
\text { FIGH 350S, } \\
\text { Fujikura or } \\
\text { HDIG, Sumita }\end{array}$ & Acriflavine & 10 & 10 & $\begin{array}{c}\text { Mean age }-67.7 \\
\text { years } \\
\text { M-80\% } \\
\text { F-20\% }\end{array}$ & Conventional histopathology \\
\hline 2016 & Oetter et al. & Germany & NS & In vivo & 6 & $\begin{array}{l}\text { Cellvizio, } \\
\text { Mauna Kea } \\
\text { Technologies, } \\
\text { Paris, France }\end{array}$ & $\begin{array}{l}\text { Fluorescein } \\
\text { Alcon }\end{array}$ & NS & 95 & NS & Conventional histopathology \\
\hline 2016 & $\begin{array}{l}\text { Linxweiler M } \\
\text { et al. }\end{array}$ & Germany & $\begin{array}{c}\text { Tonsil cancer }(26 \%), \text { tongue } \\
\text { base cancer }(24 \%), \\
\text { hypopharyngeal cancer }(15 \%) \text {, } \\
\text { tongue cancer }(10 \%) \text {, cancer of } \\
\text { the soft palate }(8 \%), \text { cancer of } \\
\text { the pharyngeal wall }(7 \%), \\
\text { cancer of the floor of the } \\
\text { mouth }(6 \%) \text {, cancer of the } \\
\text { buccal mucosa }(3 \%)\end{array}$ & Ex vivo & 12 & $\begin{array}{c}\text { Cellvizio system } \\
\text { (Mauna Kea } \\
\text { Technologies, } \\
\text { Paris, France }\end{array}$ & $\begin{array}{c}\text { Acriflavine } \\
\text { hydrochloride }\end{array}$ & 99 & 185 & NS & Conventional histopathology \\
\hline 2014 & Nathan C et al. & USA * & $\begin{array}{c}\text { Tongue }(66.6 \%), \\
\text { tonsil }(4.7 \%), \\
\text { vocal cord }(14.2 \%), \\
\text { epiglottis }(4.7 \%), \\
\text { floor of mouth }(4.7 \%), \\
\text { retromolar triangle }(4.7 \%)\end{array}$ & In vivo & 4 & $\begin{array}{c}\text { CellVizio; } \\
\text { Mauna Kea } \\
\text { Technologies, } \\
\text { Paris, France }\end{array}$ & $\begin{array}{l}\text { Fluorescein } \\
\text { Alcon }\end{array}$ & 21 & 21 & $\begin{array}{c}\text { Mean Age-64.2 } \\
\text { years } \\
\mathrm{M}-47.6 \% \\
\mathrm{~F}-52.3 \%\end{array}$ & Conventional histopathology \\
\hline
\end{tabular}

* Abbreviations: CLE—Confocal Laser Endomicroscopy, M-Males, F—Females, NS—Not Specified, NY—New York, USA—United States of America. 
Two out of the six included studies did not specify the patient details of mean age, number of males and females. The average percent of males and females across the remaining four studies were $62.2 \%$ and $37.8 \%$ respectively. The manufacturer of the CLE devices CellVizio, Vivascope 2500, FIGH-300S and CONVIVO was Mauna Kea Technologies (Paris, France), Lucid Inc. (Lucid Technologies, Henrietta, NY, USA), Fujikura or HDIG (Sumita) and Carl Zeiss AG (Oberkochen, Germany), respectively. The majority of studies were carried out in Germany. One study did not specify the site of OSCC in oral cavity [56]. Confocal criteria for OSCC diagnosis varied considerably between studies (Table 2).

Table 2. Criteria utilised for diagnosis of oral squamous cell carcinoma by the studies included in this review.

\begin{tabular}{cl}
\hline Author, Year, [Reference] & \multicolumn{1}{c}{ Laser Confocal Endoscopy Microscopic Criteria } \\
\hline Dittberner, A, 2021 [59] & $\begin{array}{l}\text { Chronic inflammation, dysplasia-free normal tissue, none to severe artefact classification, } \\
\text { tissue architecture, cell morphology, fluorescence leakage, and the vessels. }\end{array}$ \\
\hline Shinohara S, et al., 2020 [58] & Uniformity of nuclear size and shapes, cell density, nuclei and cytoplasm of cells \\
\hline Shavlokhova V, 2021 [57] & $\begin{array}{l}\text { Disturbed polarity of the basal cells, basal cell hyperplasia, irregular epithelial } \\
\text { stratification or disturbed maturational sequence, cellular pleomorphism/anisocytosis, } \\
\text { nuclear hyperchromatism, prominent nucleoli, intraepithelial keratinization, increase in } \\
\text { nuclear cytoplasmic ratio }\end{array}$ \\
\hline Oetter et al., 2016 [56] & \begin{tabular}{l} 
Homogeneity, intercellular gaps, cell morphology, fluorescein leakage, vessel morphology \\
\hline Linxweiler M et al., 2019 [55]
\end{tabular} \\
$\begin{array}{l}\text { Variable cellular morphology, lack of cytoplasmic membranes, and a hazy, } \\
\text { moth-eaten appearance. }\end{array}$ \\
\hline Nathan C et al., 2014 [25] & Normal or non-dysplasia, dysplasia, or cancer. \\
\hline
\end{tabular}

Risk of bias and quality assessment of study reports. The outcome of the methodological quality assessment of the included studies is explained in Table 3.

Table 3. Methodological assessments using QUADAS-2 tool. Each domain is assessed for risk of bias and first three for their applicability concerns.

\begin{tabular}{|c|c|c|c|c|c|c|c|c|}
\hline \multirow[t]{2}{*}{ Studies } & \multicolumn{2}{|c|}{$\begin{array}{c}\text { Domain } 1 \\
\text { Patient Selection }\end{array}$} & \multicolumn{2}{|c|}{$\begin{array}{c}\text { Domain } 2 \\
\text { Index Test(s) }\end{array}$} & \multicolumn{2}{|c|}{$\begin{array}{c}\text { Domain } 3 \\
\text { Reference Standard }\end{array}$} & \multirow{2}{*}{$\begin{array}{c}\text { Domain } 4 \\
\text { Flow \& Timing } \\
\text { Risk of Bias }\end{array}$} & \multirow{2}{*}{$\begin{array}{l}\text { Total } \\
\text { Score }\end{array}$} \\
\hline & $\begin{array}{l}\text { Risk of } \\
\text { Bias }\end{array}$ & $\begin{array}{l}\text { Applicability } \\
\text { Concerns }\end{array}$ & $\begin{array}{l}\text { Risk of } \\
\text { Bias }\end{array}$ & $\begin{array}{l}\text { Applicability } \\
\text { Concerns }\end{array}$ & $\begin{array}{l}\text { Risk of } \\
\text { Bias }\end{array}$ & $\begin{array}{l}\text { Applicability } \\
\text { Concerns }\end{array}$ & & \\
\hline Dittberner A, et al. & Low & Low & Low & Low & Low & Low & Low & 0 \\
\hline Shinohara S, et al & Low & Unclear & High & Low & High & High & Low & 7 \\
\hline Shavlokhova V, et al & Low & Low & Low & Unclear & Low & Low & High & 3 \\
\hline Oetter $\mathrm{N}$, et al & Unclear & Low & Low & Low & Low & Low & High & 3 \\
\hline Linxweiler M, et al & Low & High & Unclear & Low & Low & Low & Low & 3 \\
\hline Nathan C, et al & Low & Low & Low & Unclear & Low & Unclear & High & 4 \\
\hline
\end{tabular}

(Low-low risk (0 points), high-high risk (2 points) or unclear-unclear risk (1 point)).

The included studies exhibited low or unclear risk for bias and applicability concerns in all domains. One study $(16.66 \%)$ had an unclear $(n=1)$ risk of bias regarding patient selection with an indeterminate patient selection procedure. Five studies completely described the patient selection protocol. One study presented high and uncertain applicability concerns due to restrictions applied to the studied population (including lesions of suspected premalignancy and malignancy) and inclusion of the contralateral oral mucosa of patients, which overlooks the concept of field cancerization and applicability of the tool.

Two out of the six included studies had a high risk of bias or unclear risk of bias concerning the index test being mostly attributed to the blinding of investigators to patient characteristics. Most of the studies had low applicability concerns in the index test area due to clear demarcation of malignant changes in the observed epithelial cells.

Five of the included studies had a low risk of bias concerning the use of the reference standard due to clearly defined histopathological and confocal criteria, only one study had 
no clear diagnostic criteria and were at high risk of bias due to inadequate referencing standards. With respect to applicability concerns of the reference standard, only one study had a high risk due to the reference standard determined by an expert clinical diagnosis, whilst one study did not specify the assessors' experience level.

According to the QUADAS-2 tool, in the domain of flow and timing, three studies had a high risk of bias as these studies comprised a fair number of all benign and suspected dysplastic lesions.

\subsection{Diagnostic Accuracy of CLE and Meta-Analysis}

Whilst there are limitations to the conclusions that be drawn from a meta-analysis, the meta-analysis does give a general overview of the calculated sensitivity and specificity of any confocal microscope in different situations. Although, the studies used dissimilar tools in different settings, the actual point estimates of sensitivity and specificity depict 'threshold effect' in diagnostic clinical research.

All six studies were included in the meta-analysis. The results of the meta-analysis are reported but with its limitations, and attention against variation and potential biases. Sensitivity ranged from $71.4 \%$ to $99.3 \%$ and specificity ranged from $80 \%$ to $100 \%$. The analysis revealed a pooled sensitivity and specificity of $95 \%\left(95 \% \mathrm{CI}, 92.9-97 \% ; \mathrm{I}^{2}=77.5 \%\right)$ and $93 \%$ (95\% CI, 90-95\%; $\mathrm{I}^{2}=68.6 \%$ ). The plot of CLE sensitivity and specificity with the summary values in the diagnosis of OSCC in the involved studies is illustrated in Figure 2.

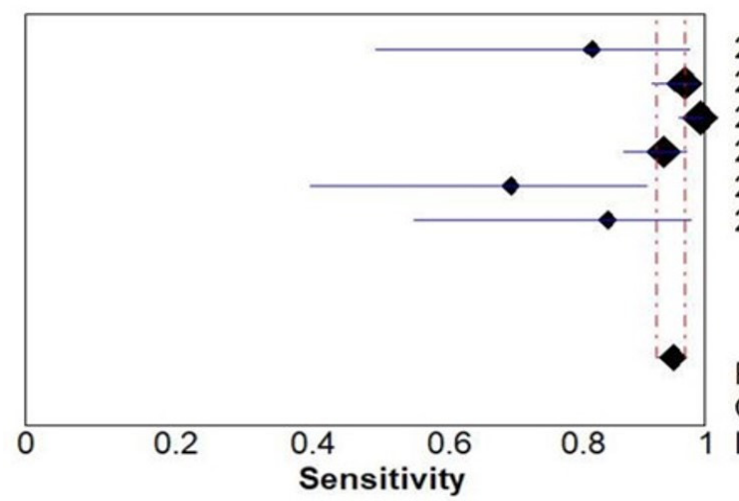

2014, Nathan C et al 2016, Linxweiler $M$ et al, 2016, Oetter et al 2020, Shavlokhova V, et al. 2020, Shinohara S, et al 2021 Dittberner A, et al.

Sensitivity

Inconsistency (I-square) $=77.5 \%$
Sensitivity $(95 \% \mathrm{Cl})$

$0.83 \quad(0.52-0.98)$

$0.97 \quad(0.92-0.99)$

$0.99 \quad(0.96-1.00)$

$0.94(0.88-0.98)$

$0.71 \quad(0.42-0.92)$

$0.86 \quad(0.57-0.98)$

Pooled Sensitivity $=0.95(0.93$ to 0.97$)$

Chi-square $=22.20 ; \mathrm{df}=5(\mathrm{p}=0.0005)$

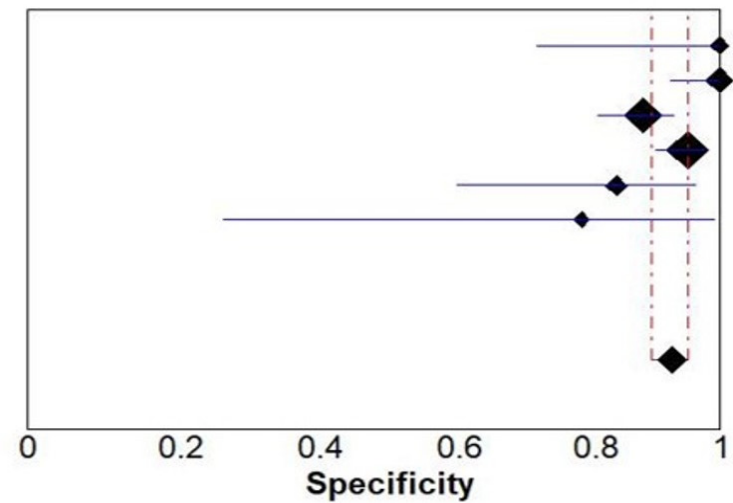

2014, Nathan C et al 2016, Linxweiler M et al, 2016, Oetter et al 2020, Shavlokhova V, et al. 2020 , Shinohara S, et al 2021 Dittberner A, et al.

Specificity $(95 \% \mathrm{Cl})$

$1.00 \quad(0.74-1.00)$

$1.00 \quad(0.93-1.00)$

$0.89 \quad(0.82-0.94)$

$0.95 \quad(0.91-0.98)$

$0.85 \quad(0.62-0.97)$

$0.80(0.28-0.99)$

Pooled Specificity $=0.93(0.90$ to 0.95$)$

Chi-square $=15.91 ; \mathrm{df}=5(\mathrm{p}=0.0071)$

Inconsistency (I-square) $=68.6 \%$

Figure 2. Forest plots for each specific study and their pooled estimates of sensitivity and specificity with their heterogeneity statistics of confocal laser endomicroscopy for the diagnosis of oral squamous cell carcinoma.

The positive likelihood ratio ranged from 4.28 ( $95 \%$ CI, $0.73-25.06)$ to 98.5 (95\% CI, 6.24-1554.1) and the negative likelihood ratio extended from 0.008 (95\% CI, 0.001-0.055) to 0.3 (95\% CI, 0.14-0.78). The pooled positive likelihood ratio and negative likelihood ratios were $10.85(95 \% \mathrm{CI}, 5.4-21.7 ; \mathrm{I} 2=55.9 \%)$ and $0.08(95 \% \mathrm{CI}, 0.03-0.2 ; \mathrm{I} 2=83.5 \%)$. 
The estimated diagnostic odds ratio (DOR) ranged from 14.1 (95\% CI, 2.61-76.6) to 2861.7 (95\% CI, 151.3-54,123.7). The pooled DOR was 174.45 (95\% CI, 34.51-881.69; I2 = 73.6\%).

The form of the HSROC curve in Figure 3 and the estimated area under the curve (AUC) was 0.97, which suggested the absence of a threshold effect. The summary ROC curve in Figure 3 describes that effect, which explains most of the heterogeneity in these studies. Additionally, the random-effects method considered the variation between studies. The shape of the prediction region is a graphic illustration of the amount of heterogeneity between studies. It is reliant on the conjecture that the data follows a normal distribution and should therefore not be over-interpreted.

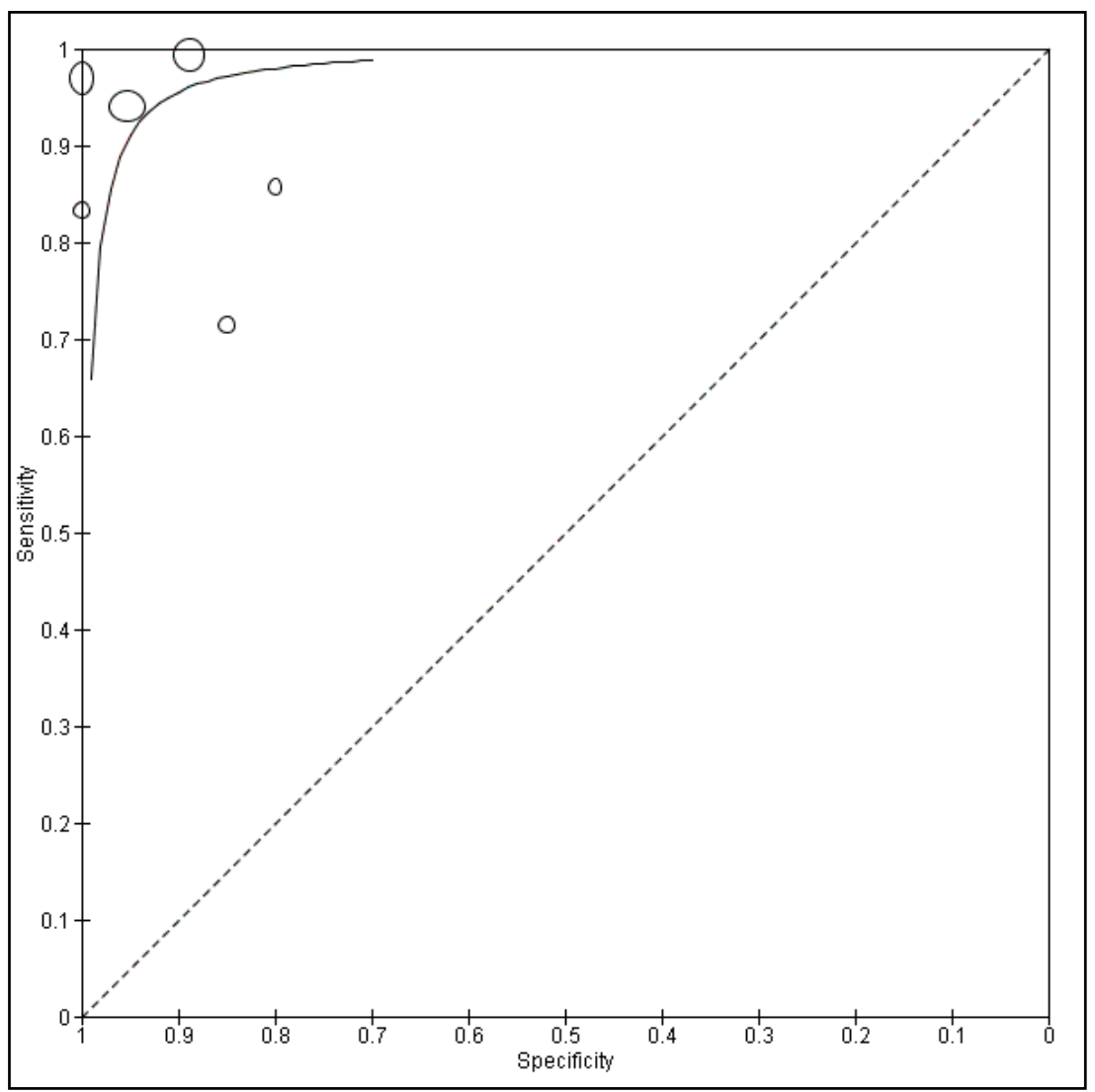

Figure 3. HSROC (hierarchal summary receiver operating characteristic) curve of sensitivity (Y-axis) vs. specificity (X-axis) of CLE for diagnosing OSCC. Points characterize the sensitivity and specificity of a single study. The sample size of the study was proportional to the size of the point. The solid line displays the summary ROC curve.

\subsection{Heterogeneity Analysis}

With reference to heterogeneity analysis, a Spearman correlation coefficient of 0.314 $(p=0.544)$ was calculated which proposed the lack of a threshold effect. Statistical analysis of the sources of heterogeneity was not performed as subgroups were too small (two or three studies per group).

The foundations of bias include variation in (i) sites within the oral cavity assessed; (ii) type of CLE device; and (iii) level of CLE training of the reviewers.

As per the general methodology rules specified for Cochrane reviews [60], "tests for funnel plot asymmetry (to assess publication bias) should be used only when there are at least 10 studies included in the meta-analysis, because when there are fewer studies the power of the tests is too low to distinguish chance from real asymmetry." As six studies have been included in the meta-analysis, a funnel plot was not performed.

Based on latest epidemiological data [4], the global prevalence of OSCC is $2 \%$. Using existing data along with the results of this study, the total number of true positives, 
false positives, true negatives, and false positives can be projected in a hypothetical cohort of 1000 patients. This means that 20 patients in this cohort would have OSCC. If we use CLE as a diagnostic tool for OSCC (sensitivity of $95 \%$ and a specificity of $93 \%$ ), one of these 20 OSCCs would go undetected, while 69 patients would be needlessly treated (Figure 4).

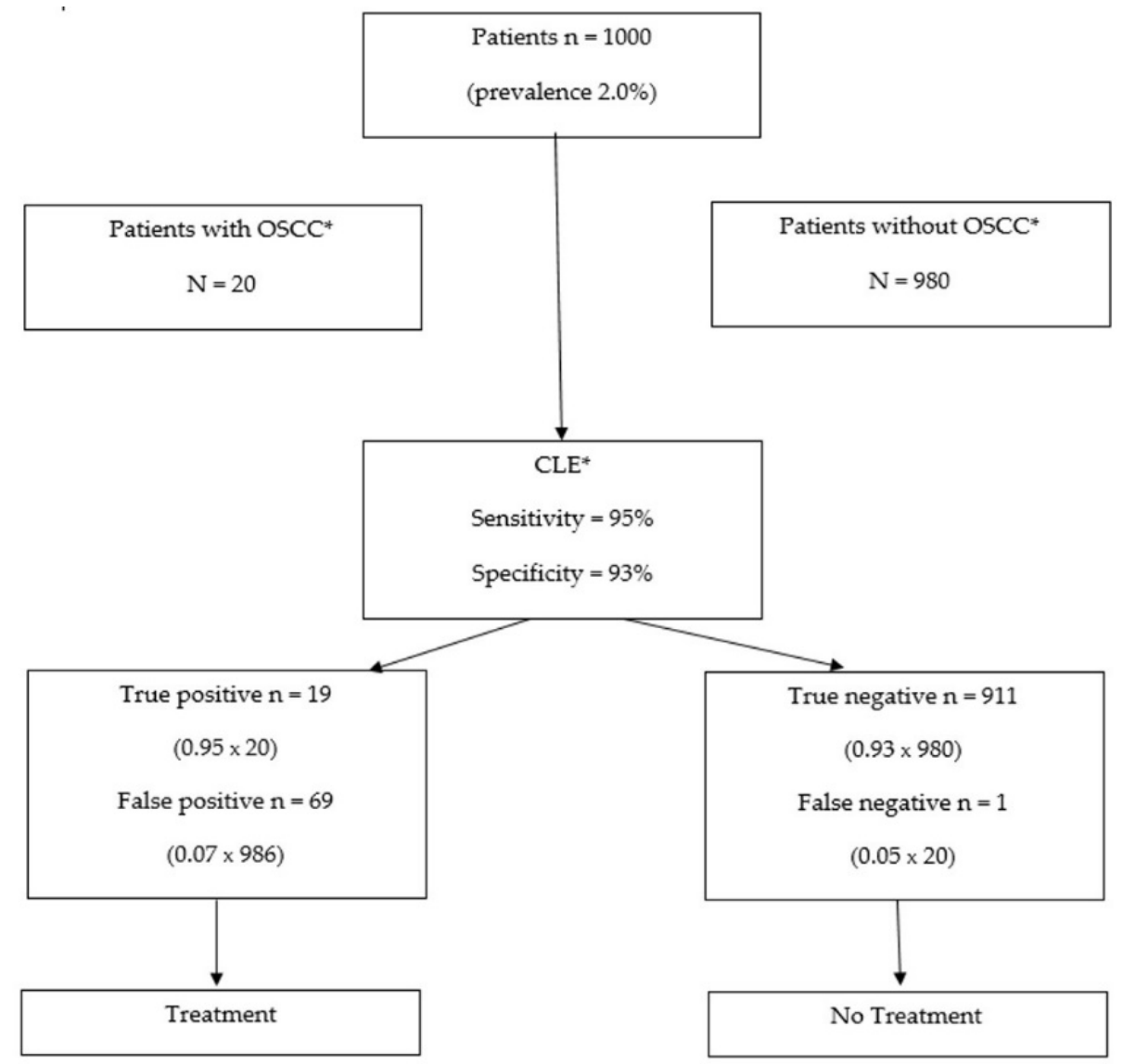

Figure 4. The use of CLE for OSCC diagnosis in a cohort of 1000 subjects. CLE would lead to 88 patients being treated, of which 69 would not need to be treated; 911 patients would not receive treatment, of which only one would have demanded treatment. * Abbreviations: OSCC—Oral Squamous Cell Carcinoma; CLE-Confocal Laser Endomicroscopy.

\section{Discussion}

CLE is a potentially useful diagnostic tool that is non-invasive and allows real-time cellular imaging of the epithelium of the upper layers of the epithelium at resolutions comparable to histology. The criteria for CLE diagnosis of OSCC are easy to learn and even non-experts in the field of CLE have been able to make a precise diagnosis of OSCC by using these criteria [56]. Previous research has indicated the efficient and precise ability of CLE to envisage dysplastic head and neck squamous cell mucosa, with close reproducibility of the histopathological diagnosis $[61,62]$.

This systematic review and meta-analysis compares histopathological diagnosis from in/ex vivo specimens to the diagnostic precision of CLE by means of analysing the results of 6 studies which comprised a total of 361 lesions. The search strategy used wide-ranging keywords in various relevant databases to find as many studies as possible.

The outcomes of the meta-analysis indicate a sensitivity of $95 \%$ and a specificity of $93 \%$ when using CLE for diagnosis of OSCC. However, care must be taken while interpreting these extraordinary values of both sensitivity and specificity. The substantial heterogeneity indicates the direct assessment of the diagnostic accuracy of CLE amongst the included studies improbable. CLE sensitivity for the diagnosis of OSCC ranged between $71.4 \%$ to $99.3 \%$, and its specificity ranged between $80 \%$ and $100 \%$. Though statistically 
insignificant (most likely due to inadequate statistical power), the discrepancies could still be explained by the diverse confocal criteria and dissimilar experimental designs (in vivo vs. ex vivo), but also investigator skill, and most likely other indefinite heterogeneity sources. Even when utilising similar diagnostic criteria, the experience of an investigator could have an influence on the diagnostic accuracy as it has been demonstrated that there is a strong correlation of expertise level and the interpretation accuracy [57].

Of the six studies included in our review, three are ex vivo $[55,57,58]$ in design and three are in-vivo $[25,56,59]$ in design. However, when comparing the CLE images for freshfrozen and formalin-fixed tissue from the patients, only marginal differences (regarding the range of brightness) in morphology were observed, with no variation in the resolution of the images. Thus, it can be stipulated that the images on ex vivo specimens would be largely reproducible in an in vivo situation [55].

\subsection{Clinical Relevance}

The efficiency and acceptability of this instrument has been addressed in the study by Nathan C et al. [25], in which they explain the advantage of CLE imaging as it decreases the sampling errors encountered during tissue biopsy or could lead to the decision of avoiding a biopsy altogether and leading to real-time management decisions.

The gold standard treatment for oral dysplastic lesions is excision or laser ablation, and lower grade suspicious lesions are usually kept under observation, due to possible chances of regression (9-45\%) [63]. However, this decision is highly criticised due to higher rates of recurrence, metastasis, and incipient malignant progressions, and it is argued that clinical examinations and palpations are insufficient in determining the malignant potential of a visually low suspicious presentation of a lesion [64]. Hence, there is the potential utilization of CLE as a surveillance tool, which could aid in diagnosing which lesions can be observed instead of being resected and which lesions demand enhanced management.

In vivo CLE could develop into a very valuable and beneficial instrument in the diagnosis of OSCC; but, to be regarded as an adjunct to the gold standard reference of histopathology, this non-invasive technique ought to have the capacity to distinguish between the histopathological grades of OSCC [65]. Although the treatment strategies for OSCC are largely based on the TNM staging of the tumour [66], the histopathological grade is also of critical importance when strategizing the therapeutic approach to treat an OSCC patient.

\subsection{Strengths and Limitations}

The included studies had some limitations such as the improper visualization of the dorsal surface of the tongue due to the keratinized filiform papillae and the limited accuracy of detection of lesions below the superficial mucosa $[25,55]$. Most of the included studies had a small sample size and the reproducibility of the results are not reliable enough to make concrete diagnosis and treatment decisions [25,58,59]. Due to ex vivo experiment design, one study is limited by the unavailability of fresh-frozen tissues for all included patients [55] as this limits the reciprocation of their results. This particular study highlights the accuracy of a non-invasive sensitive imaging modality which can be used as a screening instrument. Early detection of OSCC can greatly improve the prognosis and thus help in reducing the current burden. Although it is still not a verified replacement of histopathology, its non-invasive nature does ensure a large screening based program, with early detections and treatments. However, we would like to acknowledge the fact that precancerous lesions were not recruited or considered for inclusion in this study and there is no evidence to support the fact that it may be successful to evaluate precancerous lesions. Given the accuracy and highly sensitive reproduction of cellular details, it can only be speculated that it will reproduce similar results for precancerous lesions and can be used for screening purposes. 
One of the included studies notes that no study so far has investigated the clinical and surgical utility of CLE, especially intraoperative visualization of distinct cancerous and non-cancerous tissue margins, to limit the extent of surgical invasions [55].

To enable homogeneity, future studies could consider reporting the number of lesions analyzed, the skilled experience of the investigator, and attendance of skill development courses. Development and validation of a standardized confocal criteria for OSCC diagnosis via international agreement is desirable. Global consensus is essential for this instrument to begin its journey towards replacing the invasive surgical and histopathological techniques for screening purposes

\subsection{Future Directions}

Regarding the future scope of CLE, transference of the first tentative results of CLE in the human oral cavity into an effective and evidence based clinical setting will be a crucial step. Recent research has shown an evolution of artificial intelligence algorithms and the utilization of computational methods for an accurate diagnosis and prognosis of head and neck cancers [67]. Artificial intelligence science along with precision-based optical imaging systems such as confocal microscopy greatly improve the prospects of improving screening and prognostic outcomes of OSCC.

Further studies exploring the diagnostic accuracy of in vivo confocal laser endomicroscopy for OSCC are expected in future. To help comparability of the results it is recommended that the histopathological assessment of the excisional biopsy specimen be utilized as a reference standard.

\section{Conclusions}

Confocal laser endomicroscopy is a technique that may assist in the diagnosis of oral squamous cell carcinoma. A decisive conclusion relies on an increased number of studies investigating this technique that follow a homogeneous methodological approach, which will allow for a comparable assessment.

Author Contributions: S.S., X.J. and L.M.J. contributed to the idea of this study and executed the initial documentation; All authors contributed to the strategy of the study and applied the research; S.S., X.J., L.M.J. and R.M.L. were in charge for the data procurement, assortment and analysis, and clinical understanding of the data; S.S., X.J., L.M.J., R.M.L., P.S. and R.A.M. contributed to the statistical analysis and to the understanding of the results in addition to the manuscript drafting and writing; S.S., R.M.L., P.S., R.A.M. and L.M.J. critically revised the manuscript for important intellectual content. All authors have read and agreed to the published version of the manuscript.

Funding: This research received no external funding.

Institutional Review Board Statement: Not applicable, as this study did not involve humans or animals.

Informed Consent Statement: Not applicable, as this study did not involve humans.

Data Availability Statement: This study did not report any data.

Conflicts of Interest: R.A.M. is a co-founder and director of Miniprobes Pty Ltd., a company that develops novel optical imaging systems. Miniprobes Pty Ltd did not contribute to this study. The authors declare no other conflicts of interest.

\section{References}

1. Torre, L.A.; Bray, F.; Siegel, R.L.; Ferlay, J.; Lortet-Tieulent, J.; Jemal, A. Global cancer statistics, 2012. CA Cancer J. Clin. 2015, 65, 87-108. [CrossRef]

2. Ferlay, J; Shin, H.-R.; Bray, F.; Forman, D.; Mathers, C.; Parkin, D.M. Estimates of worldwide burden of cancer in 2008: Globocan 2008. Int. J. Cancer 2010, 127, 2893-2917. [CrossRef] [PubMed]

3. Ferlay, J.; Colombet, M.; Soerjomataram, I.; Mathers, C.; Parkin, D.M.; Piñeros, M.; Znaor, A.; Bray, F. Estimating the global cancer incidence and mortality in 2018: GLOBOCAN sources and methods. Int. J. Cancer 2019, 144, 1941-1953. [CrossRef] [PubMed]

4. Bray, F.; Ferlay, J.; Soerjomataram, I.; Siegel, R.L.; Torre, L.A.; Jemal, A. Global cancer statistics 2018: GLOBOCAN estimates of incidence and mortality worldwide for 36 cancers in 185 countries. CA Cancer J. Clin. 2018, 68, 394-424. [CrossRef] [PubMed] 
5. Marur, S.; Forastiere, A.A. Head and Neck Cancer: Changing Epidemiology, Diagnosis, and Treatment. Mayo Clin. Proc. 2008, 83, 489-501. [CrossRef]

6. Jadhav, K.B.; Gupta, N. Clinicopathological prognostic implicators of oral squamous cell carcinoma: Need to understand and revise. N. Am. J. Med. Sci. 2013, 5, 671-679. [CrossRef]

7. Sciubba, J.J.; Larian, B. Oral squamous cell carcinoma: Early detection and improved 5-year survival in 102 patients. Gen. Dent. 2018, 66, e11-e16.

8. Mehrotra, R.; Yadav, S. Oral squamous cell carcinoma: Etiology, pathogenesis and prognostic value of genomic alterations. Indian J. Cancer 2006, 43, 60-66. [CrossRef]

9. Mohan, M.; Jagannathan, N. Oral field cancerization: An update on current concepts. Oncol. Rev. 2014, 8, 244. [CrossRef]

10. Slaughter, D.P.; Southwick, H.W.; Smejkal, W. Field cancerization in oral stratified squamous epithelium. Clinical implications of multicentric origin. Cancer 1953, 6, 963-968. [CrossRef]

11. Yardimci, G.; Kutlubay, Z.; Engin, B.; Tuzun, Y. Precancerous lesions of oral mucosa. World J. Clin. Cases 2014, 2, 866-872. [CrossRef] [PubMed]

12. Warnakulasuriya, S.; Ariyawardana, A. Malignant transformation of oral leukoplakia: A systematic review of observational studies. J. Oral Pathol. Med. 2016, 45, 155-166. [CrossRef] [PubMed]

13. Aguirre-Urizar, J.M.; de Mendoza, I.L.; Warnakulasuriya, S. Malignant transformation of oral leukoplakia: Systematic review and meta-analysis of the last 5 years. Oral Dis. 2021, 27, 1881-1895. [CrossRef] [PubMed]

14. Chiesa, F.; Mauri, S.; Tradati, N.; Calabrese, L.; Giugliano, G.; Ansarin, M.; Andrle, J.; Zurrida, S.; Orecchia, R.; Scully, C. Surfing prognostic factors in head and neck cancer at the Millennium. Oral Oncol. 1999, 35, 590-596. [CrossRef]

15. Hinni, M.L.; Ferlito, A.; Brandwein-Gensler, M.S.; Takes, R.P.; Silver, C.E.; Westra, W.H.; Seethala, R.R.; Rodrigo, J.P.; Corry, J.; Bradford, C.R.; et al. Surgical margins in head and neck cancer: A contemporary review. Head Neck 2012, 35, 1362-1370. [CrossRef] [PubMed]

16. Cikojević, D.; Glunčić, I.; Pešutić-Pisac, V. Comparison of contact endoscopy and frozen section histopathology in the intraoperative diagnosis of laryngeal pathology. J. Laryngol. Otol. 2007, 122, 836-839. [CrossRef]

17. Miyawaki, A.; Hijioka, H.; Ishida, T.; Nozoe, E.; Nakamura, N.; Oya, R. Intraoperative frozen section histological analysis of resection samples is useful for the control of primary lesions in patients with oral squamous cell carcinoma. Mol. Clin. Oncol. 2015, 3, 55-62. [CrossRef]

18. Ravi, S.B.; Annavajjula, S. Surgical Margins and Its Evaluation in Oral Cancer: A Review. J. Clin. Diagn. Res. 2014, 8, ZE01-ZE05. [CrossRef]

19. Barroso, E.M.; Aaboubout, Y.; van der Sar, L.C.; Mast, H.; Sewnaik, A.; Hardillo, J.A.; Hove, I.T.; Soares, M.R.N.; Ottevanger, L.; Schut, T.C.B.; et al. Performance of Intraoperative Assessment of Resection Margins in Oral Cancer Surgery: A Review of Literature. Front. Oncol. 2021, 11, 1035. [CrossRef]

20. Guida, A.; Maglione, M.; Crispo, A.; Perri, F.; Villano, S.; Pavone, E.; Aversa, C.; Longo, F.; Feroce, F.; Botti, G.; et al. Oral lichen planus and other confounding factors in narrow band imaging (NBI) during routine inspection of oral cavity for early detection of oral squamous cell carcinoma: A retrospective pilot study. BMC Oral Health 2019, 19, 70. [CrossRef]

21. Vu, A.N.; Matias, M.A.T.; Matias, M.; Farah, C. Diagnostic accuracy of Narrow Band Imaging for the detection of oral potentially malignant disorders. Oral Dis. 2015, 21, 519-529. [CrossRef] [PubMed]

22. Luo, X.; Xu, H.; He, M.; Han, Q.; Wang, H.; Sun, C.; Li, J.; Jiang, L.; Zhou, Y.; Dan, H.; et al. Accuracy of autofluorescence in diagnosing oral squamous cell carcinoma and oral potentially malignant disorders: A comparative study with aero-digestive lesions. Sci. Rep. 2016, 6, 29943. [CrossRef]

23. Bagri-Manjrekar, K.; Chaudhary, M.; Sridharan, G.; Tekade, S.; Gadbail, A.; Khot, K. In vivo autofluorescence of oral squamous cell carcinoma correlated to cell proliferation rate. J. Cancer Res. Ther. 2018, 14, 553-558. [CrossRef] [PubMed]

24. Pałasz, P.; Adamski, Ł.; Górska-Chrzastek, M.; Starzyńska, A.; Studniarek, M. Contemporary Diagnostic Imaging of Oral Squamous Cell Carcinoma-A Review of Literature. Pol. J. Radiol. 2017, 82, 193-202. [CrossRef] [PubMed]

25. Nathan, C.-A.O.; Kaskas, N.M.; Ma, X.; Chaudhery, S.; Lian, T.; Moore-Medlin, T.; Shi, R.; Mehta, V. Confocal Laser Endomicroscopy in the Detection of Head and Neck Precancerous Lesions. Otolaryngol. Neck Surg. 2014, 151, 73-80. [CrossRef]

26. Martirosyan, N.L.; Eschbacher, J.M.; Kalani, M.Y.S.; Turner, J.D.; Belykh, E.; Spetzler, R.F.; Nakaji, P.; Preul, M.C. Prospective evaluation of the utility of intraoperative confocal laser endomicroscopy in patients with brain neoplasms using fluorescein sodium: Experience with 74 cases. Neurosurg. Focus 2016, 40, E11. [CrossRef]

27. Wallace, M.B.; Sharma, P.; Lightdale, C. Preliminary accuracy and interobserver agreement for the detection of intraepithelial neoplasia in Barrett's esophagus with probe-based confocal laser endomicroscopy. Gastrointest. Endosc. 2010, 72, 19-24. [CrossRef]

28. De Palma, G.D. Confocal laser endomicroscopy in the "in vivo" histological diagnosis of the gastrointestinal tract. World J. Gastroenterol. 2009, 15, 5770-5775. [CrossRef]

29. Kiesslich, R.; Burg, J.; Vieth, M.; Gnaendiger, J.; Enders, M.; Delaney, P.; Polglase, A.; McLaren, W.; Janell, D.; Thomas, S.; et al. Confocal laser endoscopy for diagnosing intraepithelial neoplasias and colorectal cancer in vivo. Gastroenterology 2004, 127, 706-713. [CrossRef]

30. Goetz, M. Colonoscopic Surveillance in Inflammatory Bowel Disease: State of the Art Reduction of Biopsies. Dig. Dis. 2011, 29, 36-40. [CrossRef]

31. Tan, J.; Quinn, M.; Pyman, J.M.; Delaney, P.M.; McLaren, W.J. Detection of cervical intraepithelial neoplasia in vivo using confocal endomicroscopy. BJOG Int. J. Obstet. Gynaecol. 2009, 116, 1663-1670. [CrossRef] 
32. Carlson, K.; Pavlova, I.; Collier, T.; Descour, M.; Follen, M.; Richards-Kortum, R. Confocal microscopy: Imaging cervical precancerous lesions. Gynecol. Oncol. 2005, 99, S84-S88. [CrossRef]

33. Pierre, M.L.; Stephen, L.; Annette, M.; Jean, C.L.R.; Marshall, A.; Calum, E.M. Confocal fluorescence microendoscopy of bronchial epithelium. J. Biomed. Opt. 2009, 14, 024008.

34. Thiberville, L.; Moreno-Swirc, S.; Vercauteren, T.; Peltier, E.; Cavé, C.; Heckly, G.B. In VivoImaging of the Bronchial Wall Microstructure Using Fibered Confocal Fluorescence Microscopy. Am. J. Respir. Crit. Care Med. 2007, 175, 22-31. [CrossRef] [PubMed]

35. Fuchs, F.S.; Zirlik, S.; Hildner, K.; Schubert, J.; Vieth, M.; Neurath, M.F. Confocal laser endomicroscopy for diagnosing lung cancer in vivo. Eur. Respir. J. 2013, 41, 1401-1408. [CrossRef] [PubMed]

36. Sonn, G.A.; Jones, S.-N.E.; Tarin, T.V.; Du, C.B.; Mach, K.E.; Jensen, K.C.; Liao, J.C. Optical Biopsy of Human Bladder Neoplasia With In Vivo Confocal Laser Endomicroscopy. J. Urol. 2009, 182, 1299-1305. [CrossRef] [PubMed]

37. Chang, T.C.; Liu, J.-J.; Liao, J.C. Probe-based confocal laser endomicroscopy of the urinary tract: The technique. J. Vis. Exp. 2013, 2013, e4409. [CrossRef] [PubMed]

38. Snuderl, M.; Wirth, D.; Sheth, S.A.; Bourne, S.K.; Kwon, C.-S.; Ancukiewicz, M.; Curry, W.T.; Frosch, M.P.; Yaroslavsky, A.N. Dye-Enhanced Multimodal Confocal Imaging as a Novel Approach to Intraoperative Diagnosis of Brain Tumors. Brain Pathol. 2013, 23, 73-81. [CrossRef] [PubMed]

39. Charalampaki, P.; Javed, M.; Daali, S.; Heiroth, H.J.; Igressa, A.; Weber, F. Confocal Laser Endomicroscopy for Real-time Histomorphological Diagnosis: Our Clinical Experience With 150 Brain and Spinal Tumor Cases. Neurosurgery 2015, 62 (Suppl. S1), 171-176. [CrossRef] [PubMed]

40. Fujita, Y.; Wei, L.; Cimino, P.J.; Liu, J.T.C.; Sanai, N. Video-Mosaicked Handheld Dual-Axis Confocal Microscopy of Gliomas: An ex vivo Feasibility Study in Humans. Front. Oncol. 2020, 10, 1674. [CrossRef]

41. White, W.M.; Rajadhyaksha, M.; González, S.; Fabian, R.L.; Anderson, R.R. Noninvasive Imaging of Human Oral Mucosa in Vivo by Confocal Reflectance Microscopy. Laryngoscope 1999, 109, 1709-1717. [CrossRef]

42. Clark, A.L.; Gillenwater, A.; Collier, T.G.; Alizadeh-Naderi, R.; El-Naggar, A.K.; Richards-Kortum, R.R. Confocal microscopy for real-time detection of oral cavity neoplasia. Clin. Cancer Res. 2003, 9, 4714-4721.

43. Just, T.; Stave, J.; Boltze, C.; Wree, A.; Kramp, B.; Guthoff, R.F.; Pau, H.W. Laser Scanning Microscopy of the Human Larynx Mucosa: A Preliminary, Ex Vivo Study. Laryngoscope 2006, 116, 1136-1141. [CrossRef] [PubMed]

44. Abbaci, M.; Temam, S.; Casiraghi, O.; Vielh, P.; Bosq, J.; Fouret, P.; Laplace-Builhé, C. Characterization of laryngeal carcinoma by confocal endomicroscopy. Head Neck Oncol. 2009, 1, O14. [CrossRef]

45. Muldoon, T.J.; Roblyer, D.; Williams, M.D.; Stepanek, V.M.; Richards-Kortum, R.; Gillenwater, A. Noninvasive imaging of oral neoplasia with a high-resolution fiber-optic microendoscope. Head Neck 2011, 34, 305-312. [CrossRef]

46. Farahati, B.; Stachs, O.; Prall, F. Rigid confocal endoscopy for in vivo imaging of experimental oral squamous intra-epithelial lesions. J. Oral Pathol. Med. 2010, 39, 318-327. [PubMed]

47. Zheng, W.; Harris, M.; Kho, K.W.; Thong, P.S.; Hibbs, A.; Olivo, M.; Soo, K.C. Confocal endomicroscopic imaging of normal and neoplastic human tongue tissue using ALA-induced-PPIX fluorescence: A preliminary study. Oncol. Rep. 2004, 12, 397-401. [CrossRef] [PubMed]

48. Thong, P.S.-P.; Olivo, M.C.; Kho, K.-W.; Zheng, W.; Mancer, K.; Harris, M.R.; Soo, K.-C. Laser confocal endomicroscopy as a novel technique for fluorescence diagnostic imaging of the oral cavity. J. Biomed. Opt. 2007, 12, 014007. [CrossRef] [PubMed]

49. Maitland, K.C.; Gillenwater, A.M.; Williams, M.D.; El-Naggar, A.K.; Descour, M.R.; Richards-Kortum, R.R. In vivo imaging of oral neoplasia using a miniaturized fiber optic confocal reflectance microscope. Oral Oncol. 2008, 44, 1059-1066. [CrossRef]

50. Haxel, B.R.; Goetz, M.; Kiesslich, R.; Gosepath, J. Confocal endomicroscopy: A novel application for imaging of oral and oropharyngeal mucosa in human. Eur. Arch. Oto Rhino Laryngol. 2010, 267, 443-448. [CrossRef] [PubMed]

51. Moher, D.; Liberati, A.; Tetzlaff, J.; Altman, D.G.; The PRISMA Group. Preferred reporting items for systematic reviews and meta-analyses: The PRISMA statement. PLoS Med. 2009, 6, e1000097. [CrossRef] [PubMed]

52. Schardt, C.; Adams, M.B.; Owens, T.; Keitz, S.; Fontelo, P. Utilization of the PICO framework to improve searching PubMed for clinical questions. BMC Med. Inform. Decis. Mak. 2007, 7, 16. [CrossRef] [PubMed]

53. Whiting, P.F.; Rutjes, A.W.S.; Westwood, M.E.; Mallett, S.; Deeks, J.J.; Reitsma, J.B.; Leeflang, M.M.; Sterne, J.A.; Bossuyt, P.M.; QUADAS-2 Group. QUADAS-2: A Revised Tool for the Quality Assessment of Diagnostic Accuracy Studies. Ann. Intern. Med. 2011, 155, 529-536. [CrossRef] [PubMed]

54. Leeflang, M.M.G.; Deeks, J.J.; Takwoingi, Y.; Macaskill, P. Cochrane diagnostic test accuracy reviews. Syst. Rev. 2013, 2, 82. [CrossRef]

55. Linxweiler, M.; Kadah, B.A.; Bozzato, A. Noninvasive histological imaging of head and neck squamous cell carcinomas using confocal laser endomicroscopy. Eur. Arch. Oto Rhino Laryngol. 2016, 273, 4473-4483. [CrossRef]

56. Oetter, N.; Knipfer, C.; Rohde, M.; Von Wilmowsky, C.; Maier, A.; Brunner, K.; Adler, W.; Neukam, F.-W.; Neumann, H.; Stelzle, F. Development and validation of a classification and scoring system for the diagnosis of oral squamous cell carcinomas through confocal laser endomicroscopy. J. Transl. Med. 2016, 14, 159. [CrossRef]

57. Shavlokhova, V.; Flechtenmacher, C.; Sandhu, S.; Pilz, M.; Vollmer, M.; Hoffmann, J.; Engel, M.; Freudlsperger, C. Detection of oral squamous cell carcinoma with ex vivo fluorescence confocal microscopy: Sensitivity and specificity compared to histopathology. J. Biophoton. 2020, 13. [CrossRef] 
58. Shinohara, S.; Funabiki, K.; Kikuchi, M.; Takebayashi, S.; Hamaguchi, K.; Hara, S.; Yamashita, D.; Imai, Y.; Mizoguchi, A. Real-time imaging of head and neck squamous cell carcinomas using confocal micro-endoscopy and applicable dye: A preliminary study. Auris Nasus Larynx 2020, 47, 668-675. [CrossRef]

59. Dittberner, A.; Ziadat, R.; Hoffmann, F.; Pertzborn, D.; Gassler, N.; Guntinas-Lichius, O. Fluorescein-Guided Panendoscopy for Head and Neck Cancer Using Handheld Probe-Based Confocal Laser Endomicroscopy: A Pilot Study. Front. Oncol. 2021, 11, 2186. [CrossRef]

60. Debray, T.P.A.; Moons, K.G.M.; Riley, R.D. Detecting small-study effects and funnel plot asymmetry in meta-analysis of survival data: A comparison of new and existing tests. Res. Synth. Methods 2018, 9, 41-50. [CrossRef]

61. Pogorzelski, B.; Hanenkamp, U.; Goetz, M.; Kiesslich, R.; Gosepath, J. Systematic intraoperative application of confocal endomicroscopy for early detection and resection of squamous cell carcinoma of the head and neck: A preliminary report. Arch. Otolaryngol. Head Neck Surg. 2012, 138, 404-411. [PubMed]

62. Just, T.; Pau, H.W. Intra-operative application of confocal endomicroscopy using a rigid endoscope. J. Laryngol. Otol. 2013, 127, 599-604. [CrossRef] [PubMed]

63. Lumerman, H.; Freedman, P.; Kerpel, S. Oral epithelial dysplasia and the development of invasive squamous cell carcinoma. Oral Surg. Oral Med. Oral Pathol. Oral Radiol. Endodontol. 1995, 79, 321-329. [CrossRef]

64. Arnaoutakis, D.; Bishop, J.; Westra, W.; Califano, J.A. Recurrence patterns and management of oral cavity premalignant lesions. Oral Oncol. 2013, 49, 814-817. [CrossRef]

65. Akhter, M.; Hossain, S.; Rahman, Q.B.; Molla, M.R. A study on histological grading of oral squamous cell carcinoma and its co-relationship with regional metastasis. J. Oral Maxillofac. Pathol. 2011, 15, 168-176. [CrossRef]

66. Almangush, A.; Mäkitie, A.A.; Triantafyllou, A.; de Bree, R.; Strojan, P.; Rinaldo, A.; Hernandez-Prera, J.C.; Suárez, C.; Kowalski, L.P.; Ferlito, A.; et al. Staging and grading of oral squamous cell carcinoma: An update. Oral Oncol. 2020, 107, 104799. [CrossRef] [PubMed]

67. Mahmood, H.; Shaban, M.; Rajpoot, N.; Khurram, S.A. Artificial Intelligence-based methods in head and neck cancer diagnosis: An overview. Br. J. Cancer 2021, 124, 1934-1940. [CrossRef] [PubMed] 